OPEN ACCESS

Edited by:

Sergio Tobon

University Center CIFE, Mexico

Reviewed by:

Jacek Pyżalski,

Adam Mickiewicz University, Poznań,

Poland

Zhiqiang Yan

Hunan Normal University, China

${ }^{*}$ Correspondence:

Yanjie Su

yjsu@pku.edu.cn

Specialty section

This article was submitted to

Educational Psychology,

a section of the journal

Frontiers in Psychology

Received: 14 March 2020

Accepted: 22 May 2020

Published: 07 July 2020

Citation:

Huang H, Liu Y and Su Y (2020)

What Is the Relationship Between

Empathy and Mental Health

in Preschool Teachers: The Role

of Teaching Experience.

Front. Psychol. 11:1366.

doi: 10.3389/fpsyg.2020.01366

\section{What Is the Relationship Between Empathy and Mental Health in Preschool Teachers: The Role of Teaching Experience}

\author{
Heqing Huang ${ }^{1}$, Yanchun $\mathrm{Liu}^{2}$ and Yanjie Su${ }^{3 *}$ \\ ${ }^{1}$ College of Preschool Education, Capital Normal University, Beijing, China, ${ }^{2}$ College of Education Science, Hubei Normal \\ University, Huangshi, China, ${ }^{3}$ School of Psychological and Cognitive Sciences, Peking University, Beijing, China
}

The present study aimed to delineate the characteristics of empathy and mental health in preschool teachers and to examine the role of empathy in preschool teachers' mental health. The sample in this study consisted of 4348 preschool teachers, who were divided into four groups according to their years of teaching experience (less than 2, 2-5, 5-10, and more than 10 years). The Chinese version of the Symptom Checklist 90 was used to measure the mental health symptoms of the participants, and the Chinese version of the interpersonal reactivity index was employed to assess various aspects of the participants' empathy. The results indicated that most symptoms increased as teaching experience increased, independent of the effect of age. The study also found that the four dimensions of empathy showed different trends across the four teaching experience groups: fantasy remained stable, empathic concerns and perspective taking showed decreasing trends, and personal distress showed an increasing trend. Moreover, the present research found a relatively complex relationship between empathy and mental health in preschool teachers: whereas fantasy and personal distress positively predicted mental health symptoms in preschool teachers, perspective taking and empathic concern negatively correlated with most of the symptoms. It seems that empathy contains both risk and protective factors for individuals' mental health, and these factors are affected by years of teaching experience.

Keywords: mental health, empathy, teaching experience, preschool teachers, empathic concern, personal distress, perspective taking

\section{INTRODUCTION}

The preschool teachers' job is an emotional effort (Lee et al., 2016). Throughout their whole career life span, preschool teachers were surrounded by various emotions, and the teachers have to feel, understand, and react to others' emotions appropriately (Ahmetoglu and Acar, 2016; Gaines et al., 2019). Empathy, the ability to connect others' feeling without losing himself/herself (Chiu and Yeh, 2017), is found to play an important role in preschool education (Ahmetoglu and Acar, 2016). Research has suggested that empathy is one of the crucial factors that influence how successful preschool teachers are in leading their personal and professional lives (Vucinic et al., 2020). 
Therefore, empathy is regarded as one of the core contents of teachers' professional development (Bullough, 2019), and significant differences were found between new and experienced teachers (Mevarech and Maskit, 2015).

As the emotional nature of teaching, empathy might be associated with teachers' mental health symptoms (Mérida-López et al., 2017). It is also possible that during the career development of preschool teachers, empathy differently correlated with mental health across different development stages. However, research on how empathy affects preschool teachers' mental health is sparse. The present study aimed to examine the relationship between empathy and mental health, and the role of teaching experience in the relationship.

\section{Preschool Teachers' Mental Health Status}

According to the World Health Organization (2006), mental health is a state of well-being that enables individuals to successfully cope with the normal stresses of life and work productively and contribute to their community. Mental health and its assessment are one of the broadest and most complicated issues in psychology given the many contributing factors (Keyes et al., 2002; Franken et al., 2018), and adverse symptoms, for example, depression, anxiety, and somatization, reflect aspects of mental health status (Chekroud et al., 2017).

Teaching has one of the highest rates of stress and burnout, which interfere with mental health (Grayson and Alvarez, 2008; Miller et al., 2019). The issue of mental health and well-being in teachers is critical not only for their teaching performance but also for the students (Dods, 2016; Miller et al., 2019). On the one hand, plenty of research has reported a positive relationship between teachers' mental health status and their job satisfaction and efficacy beliefs (Allan et al., 2016) and negative relationships between mental health status and burnout and depression (Jennings et al., 2017; Capone and Petrillo, 2018), which sometimes even leading to teachers' leaving their professions (Bowles and Arnup, 2016). On the other hand, teachers' mental health is correlated with the students' developmental outcomes (McLean and Connor, 2018). A recent study found that secondary teachers' better mental health was associated with students' better well-being and lower psychological distress (Harding et al., 2019).

In regard to the status of preschool teachers' mental health, the results are mixed. Although a recent meta-analysis suggested that in China, preschool teachers' mental health conditions are at least as good as, if not better than, those of other kinds of teachers, for example, primary and secondary teachers (Fan et al., 2016); other research has reported different results, indicating that education is a work context in which professionals (teachers) are likely to suffer from burnout, which may be associated with low levels of mental health (Zhang et al., 2014). Compared with K-12 teachers, preschool teachers scored higher than Chinese national controls on the SCL-90 (Chen, 2009), but more detailed information concerning preschool teachers is absent. Accordingly, the present study aims to determine the status of preschool teachers' mental health.

\section{Preschool Teachers' Empathy and Its Role in Their Mental Health}

Empathy, the capacity to feel and understand the emotion of others, is widely accepted as a multifaceted construct that contains both cognitive and affective components (Preston and de Waal, 2002; Buck et al., 2017). Among a variety of empathy multicomponent assumptions, Davis's (1983) point of view is representative. According to him, empathy contains four components: personal distress, empathic concern, fantasy, and perspective taking. Among these components, perspective taking, which is the trend and ability to walk in others' shoes, is a typical cognitive component. Although both personal distress and empathic concern are regarded as emotional components, they are believed to have opposite functions, with personal distress making individuals focus on themselves and empathic concern enabling individuals to attend to the others. In addition, fantasy is individuals' abilities and trends to transpose themselves into fictional situations. Another representative multicomponent assumption is Preston and de Waal's (2002) russian doll model of empathy, which assumed that empathy is a layered structure, with personal distress and emotional contagion in its emotional core, the more advanced form of empathy (a mixture of emotional and cognitive components, e.g., empathic concern) in the middle layer, and cognitive component (e.g., perspective taking) in the outer layer. Decety and Lamm (2006) also built a social neuroscience model of empathy, which argues that empathy involves both emotion sharing (bottomup information processing) and the regulation and modulation to this experience (top-down information processing); and the feeling of empathic concern is the outcome of the experience being regulated.

Empathy enables teachers to feel and understand what the child is feeling, communicate about the feeling with him/her, and then responding in ways that meet his/her needs. In preschool settings, each aspect of empathy plays an important role in guiding interactions between the teacher and child. For example, when encountering a crying child, a preschool teacher may have multiple empathy reactions: she/he may feel anxious and upset and may urge the child to stop crying (the feeling of personal distress), she/he may feel warm and soft-hearted and want to help the child (the feeling of empathic concern), or she/he may also consider cognitively what has happened to the child (perspective taking). In addition, the preschool teacher's responding with the child may also be automatically affected by the fictional characters in books or films that she/he have encountered.

As early education settings are highly emotionally demanding, empathy is usually regarded as a trait and a skill necessary for the teaching and caring for children, and teacher empathy emerges as a highly desirable trait (Peck et al., 2015). However, what is the role of empathy in teachers' well-beings and mental health? Previous research concerning the relationship between empathy and mental health is mixed. Both positive and negative 
relationships were found between empathy and mental healthrelated issues.

On the one hand, empathy was proved to correlated with individuals' better social relationship (Coutinho et al., 2014), higher well-being (Carnicer and Calderón, 2014), greater professional satisfaction (Halpern, 2003), and emotional selfefficacy (Goroshit and Hen, 2014), and all these issues have a close relationship with one's mental health (Wacker and Dziobek, 2018). There are also evidence that empathy is a protective factor of burnout in physicians (Lamothe et al., 2014; Thirioux et al., 2016). Empathy can also improve one's emotional state, as empathy is proposed to be a method of interpersonal emotion regulation, which have proved to be healthy and efficient (Zaki, 2019). On the other hand, researchers have also noticed the relationship between empathy and mental health symptoms. For example, empathy was found to be positively related with depression (Zhang et al., 2013) and anxiety (Fulton, 2012; Gambin and Sharp, 2018). The risk role of empathy in mental health was especially obvious in helping professionals; for example, empathy was found to have a close relationship with burnout and secondary trauma in caregivers (Kim, 2017), physicians (Tone and Tully, 2014), social workers (Macritchie and Leibowitz, 2010), and so on.

The mixed results may stem from the complication of both empathy and mental health. Although the multicomponent assumption of empathy has been wildly accepted, most of the research mentioned above does not especially examine how different dimensions of empathy correlated with mental healthrelated issues. Further investigation of the studies mentioned above implied that most of the research supporting the protective effect of empathy in mental health is biased to the cognitive aspect of empathy (Dekel et al., 2017), whereas research found that a risk role of empathy in mental health problems is focused on the emotional aspect of empathy (Williams, 1989; Dekel et al., 2017). Accordingly, we hypothesize that emotional empathy is prone to mental health problems whereas cognitive empathy plays a protective role in the among this research.

In this research, we will examine this complex relationship between empathy and mental health. Moreover, we also want to examine this relationship in preschool teaching profession, which is a typical helping profession (Erera, 1997) and a kind of emotional labor (Philipp and Schüpbach, 2010).

\section{The Role of Teaching Experience}

Teaching experience is a critical variable that should not be neglected when considering the mental health and empathy of teachers. Researchers have found that teaching experience, not age, correlates with variables related to empathy and mental health in educational settings. Researchers have found a relationship between working experience and mental health in both educational and non-educational contexts. For example, in physicians, professional experience negatively related with mental health (Yekta et al., 2014; Dai et al., 2015); in teachers, teaching experience contributed to the negative emotions concerning their professional identities (Mevarech and Maskit, 2015). Experience is also found to be related with empathy. For example, in psychiatrists, subjects with more years of experience had lower empathic concern scores (SantamaríaGarcía et al., 2017); in preservice preschool teachers, years of study is also found to correlate with various dimensions of empathy (Huang et al., 2018).

Katz (1972) has emphasized that teaching experience is one of the core variables of preschool teachers' characters. Based on Katz's theoretical frame, the growth of preschool teachers generally proceeds in four stages: survival, consolidation, renewal, and maturity. It is theoretically assumed that in different developmental stages, teachers have different psychological characteristics; however, from the empirical perspective, to date, we do not know how teaching experience affects preschool teachers' mental health and empathy across Katz's four stages. We hypothesize that in different stages of teacher development, empathy plays different roles in preschool teachers' mental health.

\section{THE PRESENT STUDY}

Briefly, the purpose of the present study is to investigate the dynamic aspects of empathy and mental health and their relationship, as well as the effect of teaching experience on these factors. There are two hypotheses in this study. The first hypothesis is that empathy dimensions correlate with mental health differently, emotional dimensions may be risk factors, and cognitive dimensions may be protective factors to the teachers' mental health. The second hypothesis is that teaching experience plays critical roles in the relationship between mental health and empathy of preschool teachers.

\section{MATERIALS AND METHODS}

\section{Participants}

The original sample consisted of 4343 preschool teachers, as 42 respondents' data were deleted from the analyses because of incomplete information, and the final sample consisted of 4301 preschool teachers from 544 preschools. These preschools were distributed throughout the 19 administrative districts in Beijing City and its surroundings. All the preschools were public, and in 2015, when the data for the present study were collected, there were 913 public preschools and approximately 21,000 preschool teachers in the Beijing area (Beijing Municipal Government, 2017); thus, approximately $51.58 \%$ of the preschools and $20.48 \%$ of preschool teachers participated in the present study. The participating preschools were randomly selected. According to the Chinese Ministry of Education (2012), all public preschools in China can be classified into four categories-model preschools, first-class preschools, second-class preschools, and third-class preschools-according to more than 10 criteria, for example, the preschools' site size and hardware level, numbers of students and teaching staff, and the quality of courses and activities. The local educational authorities conduct comprehensive assessments of each preschool according to these criteria every 3 years. In the present study, $11 \%$ of the preschool teachers were from the model preschools, $22 \%$ were from the first-class preschools, and 
$31 \%$ were from the second-class preschools. The teachers in each preschool were selected randomly and asked to complete the questionnaires through mobile phones or computers.

The age range of the final sample was 18.10 to 59.06 years, with a mean age of 30.07 years $(S D=8.44)$, and the participants' teaching experience ranged from 0.12 to 44.00 years $(M=8.11$; $\mathrm{SD}=8.10$ ). To compare the teaching experience of the preschool teachers, we divided the sample into four groups according to Katz's (1972) theory concerning preschool teachers' career development: less than 2 years of teaching experience $(n=1237)$, 2-5 years of teaching experience $(n=1138), 5-10$ years of teaching experience $(n=638)$, and more than 10 years of teaching experience $(n=1294)$. The detailed demographic characteristics of the respondents are illustrated in Table 1 . In both the whole sample and each teaching experience group, most of the participants were female (93-98.4\%) and ethnic minorities (94.194.9). The other demographic information of the participants is presented in Table 1.

\section{Procedure}

The data were collected in Spring 2016, and this research was a part of a larger cross-sectional study examining mental health and well-being in teachers. All questionnaires consisted of 200 questions and required approximately $40 \mathrm{~min}$ to complete. The questionnaires were compiled using an electronic program and released through the Beijing Preschool Education Comprehensive Service Platform, which was operated by the government, and the main users of this platform are preschool teachers and administrators. The electronic questionnaires were distributed to preschools and were answered voluntarily and anonymously by the preschool teachers. And in the introduction of this questionnaire, the participants are informed that all the information about the participants will be kept confidential and only be used for research purposes. To attend the survey, the only personal identity information that the participants are required to offer is their telephone number. The participants were asked to respond to the questionnaires through mobile phones or computers online. After completing the questionnaire, the participants drew prizes from 5 to 100 yuan, with a winning rate of $80 \%$. In addition, before the survey, the participants do not know the reward, and after all the questions were completed, the web program automatically went to a lottery page, and then the participants have the opportunity to draw.

The participants were told that these questionnaires were used to understand their feelings and common problems at work, and they were not aware of the intention of the present study. This study was approved by the Ethics Committee of the School of Preschool Education, Capital Normal University.

\section{Measures}

\section{The Chinese Version of the Symptom Checklist 90}

The Symptom Checklist 90 (SCL-90) is a 90-item multidimensional questionnaire designed to screen for a broad range of psychological problems in both clinical and non-clinical populations (Derogatis, 1992). Feng and Zhang (2001) developed the Chinese version of the SCL-90 (SCL-90-C). Similar to the SCL-90, the SCL-90-C measures participants' self-reported psychopathological features on nine subscales (each subscale comprises 6-13 items), including somatization (SOM; e.g., faintness or dizziness), obsessive-compulsiveness behavior (O-C; e.g., unwanted thoughts or ideas that will not leave your head), interpersonal sensitivity (I-S; e.g., feeling critical of others), depression (DEP; e.g., feeling low in energy or slowed down), anxiety (ANX; e.g., nervousness or shakiness inside), hostility (HOS; e.g., feeling easily annoyed or irritated), phobic anxiety (PHOB; e.g., feeling afraid in open spaces or on the street), paranoid ideation (PAR; e.g., feeling that most people cannot be trusted), and psychoticism (PSY; e.g., the idea that someone else can control your thoughts). Each question is rated according to how much the individual was bothered by the item in the last week on a 5 -point Likert scale $(0=$ "not at all," 1 = "a little bit," 2 = "moderately," 3 = "quite a bit," and 4 = "extremely"). The scores for the nine subscales were classified into three categories: average score $<1,1 \leq$ average score $<2$, and average score $\geq 2$, which corresponded to "not at all," "a little bit," and "moderately, quite a bit or extremely," respectively.

The SCL-90-C has been used in various contexts and was proved to have adequate reliability and validity among nonclinical populations in China, including within educational settings (Fan et al., 2016; Yang et al., 2019). Despite the relative large amount of items in SCL-90-C, it can detect multiple symptoms of mental health. In the present study, the SCL-90-C demonstrated adequate internal consistency for all dimensions of the questionnaire (greater than 0.74). In addition, a confirmatory factor analysis was conducted using AMOS 4.0 (Arbuckle and Wothke, 1999) to evaluate how well the specified models describe the present data. The results suggested that the SCL-90-C showed adequate structural validity, $\chi^{2} / \mathrm{df}=4.66$, normed fit index $(\mathrm{NFI})=0.99$, comparative fit index $(\mathrm{CFI})=0.001$, TuckerLewis index $(\mathrm{TLI})=0.007$, and root mean square error of approximation (RMSEA) $=0.036$.

\section{The Chinese Version of the Interpersonal Reactivity Index}

The Chinese version of the interpersonal reactivity index (IRI; Davis, 1983) developed by Huang and Su (2013) was used to assess the empathy of the participants. The IRI-C is a 28 -item self-report questionnaire that measures different dimensions of empathy; it comprises four 7-item subscales. The empathic concern subscale was designed to examine one's capacity to experience feelings of warmth, compassion, and concern toward another person in need (e.g., "I often have tender, concerned feelings for people less fortunate than me"). The personal distress subscale was designed to examine an individual's own negative emotions as he or she responds to stressful interpersonal situations (e.g., a reversed item, "When I see someone get hurt, I tend to remain calm"). The perspective taking subscale assesses attempts to adopt others' points of view (e.g., "I try to look at everybody's side of a disagreement before I make a decision"). The fantasy subscale was designed to examine the likelihood that an individual identifies with a fictional character (e.g., "I really get involved with the feelings of the characters in a novel"). The participants were asked to report on a 5point Likert scale ranging from 1 (does not describe with 
TABLE 1 | Demographic variables of the participants.

\begin{tabular}{|c|c|c|c|c|c|}
\hline & Group $1(n=1246)$ & Group $2(n=1146)$ & Group $3(n=645)$ & Group $4(n=1303)$ & Total $(N=4343)$ \\
\hline \multicolumn{6}{|l|}{ Marriage } \\
\hline Married & $284(22.8 \%)$ & $523(45.6 \%)$ & $487(75.5 \%)$ & 1208 (92.8\%) & 2503 (57.6\%) \\
\hline Non-married & 956 (76.7\%) & 619 (54\%) & 147 (22.8\%) & $43(3.3 \%)$ & 1767 (40.7\%) \\
\hline Divorce and other & $6(0.5 \%)$ & $4(0.4 \%)$ & $11(1.8 \%)$ & $51(4 \%)$ & $72(1.7 \%)$ \\
\hline \multicolumn{6}{|l|}{ Fertility } \\
\hline No children & 1069 (85.8\%) & 882 (77\%) & $288(44.7 \%)$ & 142 (10.9\%) & 2383 (54.9\%) \\
\hline Have children & 177 (14.2\%) & $264(23 \%)$ & 357 (55.3\%) & $1161(89.1 \%)$ & 1960 (45.1\%) \\
\hline \multicolumn{6}{|l|}{ Education } \\
\hline Specialized school & $164(13.2 \%)$ & $59(5.1 \%)$ & $15(2.3 \%)$ & $37(2.1 \%)$ & 275 (6.3\%) \\
\hline Specialty & $752(60.4 \%)$ & 503 (43.9) & $134(20.8)$ & $251(19.3 \%)$ & $1641(37.8 \%)$ \\
\hline B.A. & 321 (25.8\%) & $578(50.4)$ & $490(76 \%)$ & 1008 (77.4\%) & 2399 (55.2\%) \\
\hline Master & $9(0.7 \%)$ & $6(0.5 \%)$ & $6(0.9 \%)$ & $7(0.5 \%)$ & $28(0.6 \%)$ \\
\hline \multicolumn{6}{|l|}{ Major } \\
\hline Preschool education & $812(65.2 \%)$ & $743(64.8 \%)$ & $481(74.6 \%)$ & $1074(82.4 \%)$ & 3111 (71.6\%) \\
\hline Education & $154(12.4 \%)$ & $162(14.1 \%)$ & $130(20.2 \%)$ & $182(14 \%)$ & $630(14.5 \%)$ \\
\hline Non-education & 280 (22.5\%) & 241 (21\%) & 34 (5.3\%) & 46 (3.5\%) & 602 (13.9\%) \\
\hline \multicolumn{6}{|l|}{ Title } \\
\hline Three class & 801 (64.3) & $230(20.1 \%)$ & $84(13 \%)$ & $88(6.8 \%)$ & 1204 (27.7\%) \\
\hline Two class & $28(2.2 \%)$ & $26(21.1)$ & $59(9.1 \%)$ & 545 (41.8\%) & $659(15.2 \%)$ \\
\hline The first class & $119(9.6)$ & 358 (31.2\%) & 338 (52.4\%) & 573 (44\%) & 1389 (32\%) \\
\hline High & $93(7.5 \%)$ & $242(21.1 \%)$ & $142(22 \%)$ & $90(6.9 \%)$ & $567(13.1 \%)$ \\
\hline Very high & 204 (16.4\%) & 290 (25.3\%) & 22 (3.4\%) & $6(0.5 \%)$ & $522(12 \%)$ \\
\hline \multicolumn{6}{|l|}{ Position } \\
\hline High & $7(0.6 \%)$ & $4(0.3 \%)$ & 2 (0.3\%) & $18(1.4 \%)$ & $31(0.7 \%)$ \\
\hline Middle & $8(0.6 \%)$ & $22(1.9 \%)$ & $25(0.3 \%)$ & $145(11.1 \%)$ & 200 (4.6\%) \\
\hline Low & 1231 (98.8\%) & $1120(97.7 \%)$ & $618(95.8 \%)$ & 1140 (87.5\%) & $94.7 \%$ \\
\hline
\end{tabular}

me) to 5 (describes with me very well). All of the subscales demonstrated adequate internal reliability, with alpha values of $0.77,0.82,0.80$, and 0.81 (for empathic concern, personal distress, perspective taking, and fantasy, respectively). Structural validity was examined using AMOS 4.0 (Arbuckle and Wothke, 1999), and the results indicated that the fitness was good, $\mathrm{CMIN}=19,481.33, \mathrm{df}=4024, \chi^{2} / \mathrm{df}=3.69, \mathrm{NFI}=0.97$, $\mathrm{CFI}=0.001$, TLI $=0.008$, and RMSEA $=0.043$.

\section{RESULTS}

The descriptive analyses of the participants' mental health and empathy dimensions are shown in Table 2. In addition to the descriptive statistics, three sets of analyses were conducted. First, using $T$ tests and multivariate analysis of variance (MANOVA), the characteristics of the participants' mental health condition were examined. Second, the levels of the participants' empathy dimensions were examined. Finally, correlation and regression analyses were carried out to investigate the relationship between preschool teachers' empathy and mental health and in which the role of teaching experience plays.

\section{Preschool Teachers' Mental Health}

According to Table 2, the sample means for each subscale of the SCL-90-C were between 1 and 2, indicating that the preschool teachers exhibited mental health symptoms at levels between "a little bit" and "moderately."

To profile the teachers' performance on SCL-90-C, a 9 (types of mental health symptoms) $\times 4$ (teaching experience groups) repeated measures MANOVA was performed. Among the variables, the category of mental health symptoms was withinsubject variables, and the participants' teaching experience group was the between-subject variable. The results are shown in Figure 1. The sphericity assumption for repeated measures MANOVA was violated: Mauchly's $W_{(35)}=0.341$, $\chi^{2}{ }_{(2)}=4620.12, p<0.001$. Because violating this assumption inflates the Type I error rate, we used the Huynh-Feldt epsilon to adjust the degrees of freedom and provide a more accurate Type I error rate (Stevens, 2002). The results indicate that there are significant interactive effects between all the nine mental health symptoms and the four teaching experience groups. The interactive effect between the symptoms and teaching experience was significant, $F(24,4297)=23.13$, $p<0.001, \eta_{\mathrm{p}}^{2}=0.016, d=1.0$. Next, two sets of simple-effect analyses were conducted to analyze the interactive effect from two perspectives.

In the first simple-effect analysis, nine ANOVAs were used to determine the changing characteristics of the nine mental health symptoms across the four teaching experience groups. The results indicated that for all the nine mental health symptoms, there were significant differences between each experience groups, and 
TABLE 2 | The descriptive statistics of scores of mental health symptoms and empathy and the ANOVA analysis across the working years groups.

\begin{tabular}{|c|c|c|c|c|c|c|c|c|c|c|c|}
\hline & \multicolumn{2}{|c|}{ Group $1(n=1246)$} & \multicolumn{2}{|c|}{ Group $2(n=1146)$} & \multicolumn{2}{|c|}{ Group $3(n=645)$} & \multicolumn{2}{|c|}{ Group $4(n=1303)$} & \multirow{2}{*}{$\begin{array}{l}\text { ANOVAs across the } \\
\text { working time groups }\end{array}$} & \multicolumn{2}{|c|}{ Total $(N=4343)$} \\
\hline & $M$ & SD & $M$ & SD & $M$ & SD & $M$ & SD & & $M$ & SD \\
\hline \multicolumn{12}{|c|}{$\begin{array}{l}\text { Mental health } \\
\text { symptoms }\end{array}$} \\
\hline SOM & 1.61 & 0.64 & 1.82 & 0.73 & 1.98 & 0.78 & 2.15 & 0.82 & $F(3,4336)=119.01^{\star \star}$ & 1.88 & 0.77 \\
\hline $\mathrm{O}-\mathrm{C}$ & 1.87 & 0.68 & 2.03 & 0.72 & 2.15 & 0.77 & 2.25 & 0.80 & $F(3,4336)=60.07^{\star \star}$ & 2.07 & 0.76 \\
\hline I-S & 1.64 & 0.63 & 1.76 & 0.66 & 1.85 & 0.74 & 1.97 & 0.74 & $F(3,4336)=51.33^{\star *}$ & 1.80 & 0.70 \\
\hline DEP & 1.58 & 0.64 & 1.75 & 0.69 & 1.86 & 0.78 & 2.00 & 0.78 & $F(3,4336)=76.14^{\star \star}$ & 1.79 & 0.74 \\
\hline ANX & 1.56 & 0.59 & 1.70 & 0.67 & 1.80 & 0.74 & 1.91 & 0.74 & $F(3,4336)=60.46^{\star \star}$ & 1.74 & 0.70 \\
\hline HOS & 1.52 & 0.61 & 1.70 & 0.68 & 1.80 & 0.73 & 1.95 & 0.79 & $F(3,4336)=82.99^{\star \star}$ & 1.74 & 0.72 \\
\hline $\mathrm{PHOB}$ & 1.41 & 0.57 & 1.51 & 0.61 & 1.58 & 0.65 & 1.64 & 0.70 & $F(3,4336)=30.34^{\star \star}$ & 1.53 & 0.64 \\
\hline PAR & 1.50 & 0.60 & 1.62 & 0.62 & 1.69 & 0.67 & 1.83 & 0.70 & $F(3,4336)=55.44^{\star \star}$ & 1.66 & 0.66 \\
\hline PSY & 1.51 & 0.56 & 1.61 & 0.58 & 1.69 & 0.63 & 1.80 & 0.68 & $F(3,4336)=52.28^{\star \star}$ & 1.65 & 0.63 \\
\hline \multicolumn{12}{|c|}{ Empathy } \\
\hline FS & 3.00 & 0.58 & 3.04 & 0.60 & 3.05 & 0.60 & 2.99 & 0.58 & $F(3,4336)=2.81^{*}$ & 3.02 & 0.59 \\
\hline EC & 3.69 & 0.50 & 3.66 & 0.52 & 3.70 & 0.54 & 3.62 & 0.51 & $F(3,4336)=5.30^{* \star}$ & 3.66 & 0.52 \\
\hline PT & 3.61 & 0.60 & 3.53 & 0.59 & 3.56 & 0.62 & 3.50 & 0.57 & $F(3,4336)=7.48^{\star \star}$ & 3.55 & 0.59 \\
\hline PD & 2.73 & 0.54 & 2.84 & 0.53 & 2.85 & 0.57 & 2.89 & 0.55 & $F(3,4336)=20.10^{* *}$ & 2.83 & 0.55 \\
\hline
\end{tabular}

${ }^{*} p<0.05,{ }^{*} p<0.01$. SOM, somatization; O-C, obsessive-compulsiveness; I-S, interpersonal sensitivity; DEP, depression; ANX, anxiety; HOS, hostility; PHOB, phobic anxiety; PAR, paranoid ideation; PSY, psychoticism; FS, fantasy; EC, empathic concern; PT, perspective taking; PD, personal distress.

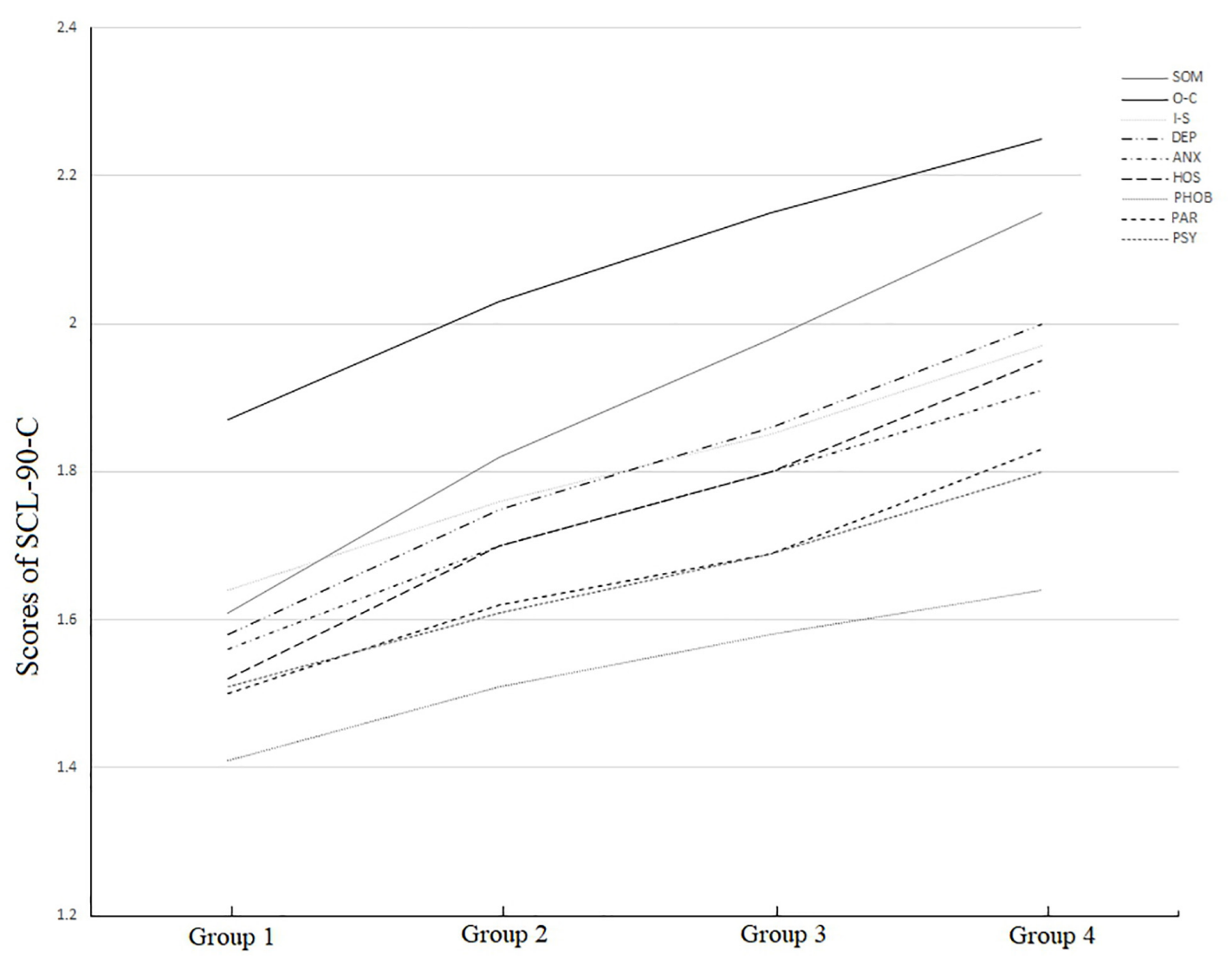

FIGURE 1 | The SCL-90-C scores of the preschool teachers form the four teachering experience groups. 
with the teaching experience increased, all the nine symptoms increased (see Table 2).

In the second simple-effect analysis, we split the data into four teaching experience groups and conducted repeated measures across the nine symptoms in each group. The results suggest that in each of the four teaching experience groups, obsessivecompulsiveness behavior, interpersonal sensitivity, somatization, and depression are the four most serious symptoms. Although in each teaching experience group obsessive-compulsiveness behavior is the most serious symptom, there were some slight differences for the other symptoms: in the group with less than 2 years of teaching experience, somatization was the second most serious symptom, and interpersonal sensitivity was the third most serious problem; in the groups with 2-5 and 5-10 years of teaching experience, the severity of somatization increased and ranked as the second most serious symptom for preschool teachers, and in this teaching experience group, depression was as serious as interpersonal sensitivity and ranked as the third most serious symptom. In the two groups with more than 5 years of teaching experience, the severity of depression outweighed the severity of interpersonal sensitivity and was the third most serious mental health symptom.

In short, the teachers in the present study exhibited mental health symptoms at levels between "a little bit" and "moderately," and they scored higher than the Chinese norm for all the nine mental health symptoms. The most serious symptoms in preschool teachers are obsessive-compulsiveness behavior, interpersonal sensitivity, somatization, and depression. The severity of all these symptoms increased with experience, and it seems that somatization and depression's severity grew faster.

\section{Preschool Teachers' Empathy}

A 4 (dimensions of empathy) $\times 4$ (teaching experience groups) repeated measures MANOVA was performed to profile the teachers' empathy, and among the variables, the empathy dimensions were within-subject variables, and the participants' teaching experience group was the between-subject variable. The sphericity assumption for repeated measures MANOVA was violated: Mauchly's $W_{(5)}=0.585, \chi^{2}{ }_{(2)}=2300.11, p<0.001$. The results indicate that there are both significant main effects of empathy dimension and interactive effects between dimensions of empathy and teaching experience, for empathy dimension, $F(3,4297)=3205.34, p<0.001, \eta_{\mathrm{p}}^{2}=0.427, d=1.0$; and for interactive effect, $F(9,4296)=15.865, p<0.001$, $\eta_{\mathrm{p}}^{2}=0.011, d=1.0$.

In the following simple-effect analyses, four ANOVAs (see Table 2) were conducted to compare levels of empathy across the four teaching experience groups, and the results suggested that the four dimensions of empathy showed different changing trends across the four teaching experience periods. For fantasy, no difference was found between any of the teaching experience groups, but for empathic concern, the first (mean difference $=0.07, p<0.01$ ) and third teaching experience groups (mean difference $=0.08, p<0.01$ ) had significantly higher scores than the fourth group. For perspective taking, the first teaching experience group had higher scores than the second (mean difference $=0.08, p<0.01$ ) and fourth teaching experience groups (mean difference $=0.11, p<0.01$ ). For personal distress, the first teaching experience group had significantly lower scores than the other three groups (mean differences $=-0.12$, -0.12 , and -0.16 , $p s<0.01$ ). It seems that in the preschool teachers, empathic concern and perspective taking showed a general decreasing trend, whereas personal distress showed an increasing trend.

\section{The Role of Empathy in Preschool Teachers' Mental Health}

Pearson correlations were conducted to explore the relationship between dimensions of empathy and mental health symptoms (see Table 3). On the basis of correlation analyses, two sets of hierarchical regression analyses were conducted to determine whether empathy predicts mental health symptoms in preschool teachers. The first set of regression analyses used the nine mental health symptoms as dependent variables (see Table 4). For these hierarchical regressions, the demographic variables were entered in Step 1, the length of teaching experience was entered in Step 2, and the four variables of empathy were entered in Step 3. For all nine hierarchical regressions, the models with the set of population measures were significant, $F$ s $\geq 19.33$, ps $<0.001$, and $R^{2} s \geq 0.019$, and we found that age significantly predicted all nine mental health symptoms. When the variable for preschool teaching experience was entered in the second step, with the exception of somatization, age did not account for any additional variance in the models, $0.02 \leq \Delta R^{2} \leq 0.09$, $0.018, F$ (change) $\geq 16.75, p<0.001$. In addition, in this step, teaching experience positively predicted all mental health symptoms, even after the effect of age was controlled. In the third set of models, the four empathy dimensions were entered and showed different predictive patterns for the nine mental health symptoms. On the one hand, both fantasy and personal distress positively predicted the nine mental health symptoms; thus, it seems that the more an individual is prone to fantasy or personal distress, the more susceptible he or she is to these mental health symptoms. On the other hand, empathic concern and perspective taking negatively predicted the nine mental health symptoms; thus, it appears that these two components are protective factors for mental symptoms.

To explore the changing pattern of empathy in mental health symptoms based on teaching experience, hierarchical regressions were conducted in each teaching experience group, with the nine mental health symptoms as the dependent variables (see Table 5). In each hierarchical regression, the demographic variables were entered in the first step, and the four dimensions of empathy were entered in the second step. The results revealed that the predictions of the four dimensions of empathy were different across the four teaching experience groups. As all first models were significant (all $F s>29.01$, ps $<0.001$ ) and to avoid an unwieldy table, we present only the second set of models in Table 5. The results revealed that fantasy and personal distress positively predicted all mental health symptoms in each teaching experience group; however, the roles 
TABLE 3 | Pearson correlations between participants' demographic variables, mental health symptoms, and dimensions of empathy.

\begin{tabular}{|c|c|c|c|c|c|c|c|c|c|c|c|c|c|c|c|c|c|c|}
\hline & 2 & 3 & 4 & 5 & 6 & 7 & 8 & 9 & 10 & 11 & 12 & 13 & 14 & 15 & 16 & 17 & 18 & 19 \\
\hline \multicolumn{19}{|c|}{ Demographic variables } \\
\hline Age & $0.81^{\star \star}$ & $0.60^{\star \star}$ & $0.72^{\star \star}$ & $0.31^{\star \star}$ & $0.19^{\star \star}$ & $0.25^{\star \star}$ & $0.16^{\star \star}$ & $0.14^{\star \star}$ & $0.19^{\star \star}$ & $0.16^{\star \star}$ & $0.16^{\star \star}$ & $0.12^{\star \star}$ & $0.15^{\star \star}$ & $0.16^{\star \star}$ & $-0.11^{\star *}$ & $-0.03^{*}$ & $-0.03^{\star}$ & $0.05^{\star \star}$ \\
\hline TE & & $0.50^{\star \star}$ & $0.59^{\star \star}$ & $0.25^{\star \star}$ & $0.15^{\star \star}$ & $0.25^{\star \star}$ & $0.17^{\star \star}$ & $0.16^{\star \star}$ & $0.19^{\star \star}$ & $0.18^{\star \star}$ & $0.19^{\star \star}$ & $0.13^{\star \star}$ & $0.17^{\star \star}$ & $0.17^{\star \star}$ & $-0.05^{\star \star}$ & $-0.05^{\star \star}$ & $-0.06^{\star *}$ & $0.08^{\star \star}$ \\
\hline Marriage & & & $0.65^{\star \star}$ & $0.34^{\star \star}$ & $0.11^{\star \star}$ & $0.19^{\star \star}$ & $0.12^{\star \star}$ & $0.11^{\star \star}$ & $0.14^{\star \star}$ & $0.12^{\star \star}$ & $0.14^{\star *}$ & $0.08^{\star *}$ & $0.12^{\star \star}$ & $0.11^{\star \star}$ & $-0.03^{*}$ & -0.01 & -0.02 & $0.05^{\star \star}$ \\
\hline Fertility & & & & $0.30^{\star \star}$ & $0.11^{\star \star}$ & $0.20^{\star \star}$ & $0.14^{\star *}$ & $0.13^{\star \star}$ & $0.16^{\star \star}$ & $0.14^{\star \star}$ & $0.15^{\star \star}$ & $0.10^{\star \star}$ & $0.13^{\star *}$ & $0.13^{\star \star}$ & $-0.06^{\star \star}$ & $-0.03^{\star}$ & $-0.04^{\star *}$ & $0.06^{\star \star}$ \\
\hline Education & & & & & $0.16^{\star \star}$ & $0.20^{\star \star}$ & $0.16^{\star \star}$ & $0.13^{\star *}$ & $0.16^{\star \star}$ & $0.14^{\star \star}$ & $0.17^{\star \star}$ & $0.08^{\star \star}$ & $0.14^{\star \star}$ & $0.14^{\star *}$ & -0.00 & -0.01 & -0.01 & $0.08^{\star \star}$ \\
\hline Income & & & & & & $0.04^{\star \star}$ & 0.03 & 0.02 & $0.04^{\star \star}$ & 0.03 & $0.03^{\star}$ & 0.02 & $0.03^{\star}$ & $0.04^{\star \star}$ & -0.02 & -0.02 & 0.00 & -0.01 \\
\hline \multicolumn{19}{|c|}{ Mental health symptoms } \\
\hline SOM & & & & & & & $0.84^{\star *}$ & $0.79^{\star \star}$ & $0.85^{\star \star}$ & $0.87^{\star \star}$ & $0.79^{\star \star}$ & $0.75^{\star \star}$ & $0.76^{\star \star}$ & $0.82^{\star \star}$ & $0.20^{\star *}$ & $0.07^{\star \star}$ & $-0.09^{\star *}$ & $0.48^{* *}$ \\
\hline $\mathrm{O}-\mathrm{C}$ & & & & & & & & $0.87^{\star \star}$ & $0.90^{\star \star}$ & $0.88^{\star \star}$ & $0.81^{\star \star}$ & $0.78^{\star \star}$ & $0.81^{\star *}$ & $0.85^{\star \star}$ & $0.38^{\star \star}$ & $0.11^{\star \star}$ & $-0.09^{\star \star}$ & $0.57^{\star \star}$ \\
\hline I-S & & & & & & & & & $0.91^{\star \star}$ & $0.89^{\star \star}$ & $0.83^{\star \star}$ & $0.83^{\star \star}$ & $0.89^{\star \star}$ & $0.90^{\star \star}$ & $0.37^{\star *}$ & $0.06^{\star \star}$ & $-0.17^{\star *}$ & $0.57^{\star \star}$ \\
\hline DEP & & & & & & & & & & $0.92^{* *}$ & $0.85^{\star \star}$ & $0.82^{\star \star}$ & $0.87^{\star \star}$ & $0.90^{\star *}$ & $0.35^{* *}$ & $0.05^{\star \star}$ & $-0.16^{\star *}$ & $0.55^{\star \star}$ \\
\hline ANX & & & & & & & & & & & $0.84^{\star \star}$ & $0.85^{\star \star}$ & $0.85^{\star \star}$ & $0.90^{\star \star}$ & $0.36^{\star \star}$ & $0.05^{\star \star}$ & $-0.14^{\star *}$ & $0.55^{\star \star}$ \\
\hline HOS & & & & & & & & & & & & $0.77^{\star \star}$ & $0.85^{\star \star}$ & $0.84^{\star *}$ & $0.32^{\star \star}$ & 0.01 & $-0.22^{\star \star}$ & $0.54^{\star \star}$ \\
\hline $\mathrm{PHOB}$ & & & & & & & & & & & & & $0.79^{\star \star}$ & $0.83^{\star *}$ & $0.29^{\star *}$ & -0.01 & $-0.17^{\star \star}$ & $0.49^{\star \star}$ \\
\hline PAR & & & & & & & & & & & & & & $0.88^{\star *}$ & $0.32^{\star *}$ & -0.02 & $-0.21^{\star *}$ & $0.49^{* \star}$ \\
\hline PSY & & & & & & & & & & & & & & & $0.34^{\star *}$ & 0.02 & $-0.17^{\star \star}$ & $0.53^{\star \star}$ \\
\hline \multicolumn{19}{|l|}{ Empathy } \\
\hline FS & & & & & & & & & & & & & & & & $0.43^{\star \star}$ & $0.20^{\star \star}$ & $0.53^{* \star}$ \\
\hline EC & & & & & & & & & & & & & & & & & $0.60^{\star \star}$ & $0.27^{\star \star}$ \\
\hline PT & & & & & & & & & & & & & & & & & & $-0.06^{\star \star}$ \\
\hline PD & & & & & & & & & & & & & & & & & & \\
\hline
\end{tabular}


TABLE 4 | Hierarchy regressions predicting the preschool teachers' mental health symptoms.

\begin{tabular}{|c|c|c|c|c|c|c|c|c|c|c|c|c|c|c|c|c|c|c|c|}
\hline & & \multicolumn{4}{|c|}{ Model 1} & \multirow[b]{2}{*}{ Age } & \multicolumn{4}{|c|}{ Model 2} & \multirow[b]{2}{*}{ Age } & \multicolumn{8}{|c|}{ Model 3} \\
\hline & & Age & Gender & Marriage & Education & & Gender & Marriage & Education & WY & & Gender & Marriage & Education & WT & FS & EC & PT & PD \\
\hline \multirow[t]{3}{*}{ SoM } & B & 0.02 & -0.19 & 0.03 & 0.16 & 0.01 & -0.14 & 0.02 & 0.16 & 0.01 & 0.01 & -0.03 & 0.01 & 0.12 & 0.01 & 0.21 & -0.08 & -0.08 & 0.54 \\
\hline & $\beta$ & 0.20 & -0.05 & 0.02 & 0.13 & 0.10 & -0.03 & 0.02 & 0.13 & 0.13 & 0.16 & -0.01 & 0.01 & 0.10 & 0.07 & 0.16 & -0.05 & -0.06 & 0.38 \\
\hline & $t$ & $11.10^{* \star}$ & $-3.15^{\star \star}$ & 1.09 & $8.24^{\star \star}$ & $3.66^{\star \star}$ & $-2.34^{\star \star}$ & 0.93 & $8.29^{\star \star}$ & $5.22^{\star \star}$ & $6.70^{\star \star}$ & -0.55 & 0.54 & $7.25^{\star \star}$ & $3.12^{\star \star}$ & $9.91^{\star *}$ & $-3.10^{\star \star}$ & $-3.70^{* \star}$ & $24.65^{\star \star}$ \\
\hline \multirow[t]{3}{*}{ O-C } & B & 0.01 & -0.08 & 0.02 & 0.14 & 0.00 & -0.04 & 0.02 & 0.14 & 0.01 & 0.01 & 0.10 & 0.00 & 0.09 & 0.00 & 0.24 & -0.08 & -0.09 & 0.65 \\
\hline & $\beta$ & 0.12 & -0.02 & 0.02 & 0.11 & 0.03 & -0.01 & 0.01 & 0.11 & 0.11 & 0.10 & 0.02 & 0.00 & 0.08 & 0.03 & 0.19 & -0.05 & -0.07 & 0.47 \\
\hline & $t$ & $6.17^{\star \star}$ & -1.30 & 0.83 & $7.06^{\star \star}$ & 1.15 & -0.67 & 0.71 & $7.09^{\star \star}$ & $4.09^{\star \star}$ & $4.59^{\star \star}$ & $2.03^{*}$ & 0.20 & $5.85^{\star \star}$ & 1.46 & $12.25^{\star \star}$ & $-3.04^{\star \star}$ & $-4.31^{\star \star}$ & $32.19^{\star \star}$ \\
\hline \multirow[t]{3}{*}{ I-S } & B & 0.01 & -0.06 & 0.01 & 0.10 & 0.00 & -0.02 & 0.01 & 0.10 & 0.01 & 0.01 & 0.10 & -0.01 & 0.06 & 0.00 & 0.24 & -0.09 & -0.16 & 0.60 \\
\hline & $\beta$ & 0.11 & -0.01 & 0.01 & 0.09 & 0.02 & 0.00 & 0.01 & 0.09 & 0.12 & 0.09 & 0.03 & 0.00 & 0.05 & 0.04 & 0.20 & -0.07 & -0.13 & 0.47 \\
\hline & $t$ & $5.98^{\star \star}$ & -0.97 & 0.47 & $5.39^{\star \star}$ & 0.63 & -0.26 & 0.34 & $5.42^{\star \star}$ & $4.63^{\star \star}$ & $4.22^{\star \star}$ & $2.13^{*}$ & -0.30 & $3.82^{\star \star}$ & $1.78^{\dagger}$ & $12.95^{\star \star}$ & $-3.93^{\star *}$ & $-8.49^{* \star}$ & $31.80^{* \star}$ \\
\hline \multirow[t]{3}{*}{ DEP } & B & 0.01 & -0.07 & 0.02 & 0.13 & 0.01 & -0.03 & 0.02 & 0.13 & 0.01 & 0.01 & 0.08 & 0.01 & 0.09 & 0.00 & 0.23 & -0.10 & -0.15 & 0.62 \\
\hline & $\beta$ & 0.14 & -0.02 & 0.02 & 0.11 & 0.05 & -0.01 & 0.01 & 0.11 & 0.11 & 0.12 & 0.02 & 0.00 & 0.07 & 0.04 & 0.18 & -0.07 & -0.12 & 0.46 \\
\hline & $t$ & $7.67^{\star \star}$ & -1.22 & 0.91 & $6.90^{\star \star}$ & $1.88^{\dagger}$ & -0.53 & 0.78 & $6.94^{\star \star}$ & $4.49^{\star \star}$ & $5.50^{\star \star}$ & 1.68 & 0.29 & $5.68^{\star \star}$ & $1.71^{\dagger}$ & $11.79^{\star \star}$ & $-4.13^{\star \star}$ & $-7.53^{\star \star}$ & $30.98^{\star \star}$ \\
\hline \multirow[t]{3}{*}{ ANX } & B & 0.01 & -0.09 & 0.01 & 0.11 & 0.00 & -0.05 & 0.01 & 0.11 & 0.01 & 0.01 & 0.06 & 0.00 & 0.07 & 0.00 & 0.22 & -0.13 & -0.10 & 0.59 \\
\hline & $\beta$ & 0.12 & -0.02 & 0.01 & 0.10 & 0.02 & -0.01 & 0.01 & 0.10 & 0.13 & 0.10 & 0.02 & 0.00 & 0.06 & 0.05 & 0.19 & -0.09 & -0.09 & 0.46 \\
\hline & $t$ & $6.64^{\star \star}$ & -1.64 & 0.54 & $6.03^{\star \star}$ & 0.82 & -0.87 & 0.40 & $6.06^{\star \star}$ & $4.97^{\star \star}$ & $4.21^{\star \star}$ & 1.37 & -0.16 & $4.56^{\star \star}$ & $2.33^{\star}$ & $12.22^{\star \star}$ & $-5.53^{\star \star}$ & $-5.38^{* \star}$ & $31.08^{\star \star}$ \\
\hline \multirow[t]{3}{*}{ HOS } & B & 0.01 & -0.08 & 0.05 & 0.14 & 0.00 & -0.02 & 0.05 & 0.14 & 0.01 & 0.00 & 0.07 & 0.04 & 0.10 & 0.01 & 0.20 & -0.11 & -0.21 & 0.59 \\
\hline & $\beta$ & 0.10 & -0.02 & 0.04 & 0.12 & -0.04 & 0.00 & 0.04 & 0.12 & 0.17 & 0.03 & 0.02 & 0.03 & 0.08 & 0.09 & 0.17 & -0.08 & -0.17 & 0.45 \\
\hline & $t$ & $5.15^{\star \star}$ & -1.33 & $2.26^{*}$ & $7.53^{\star \star}$ & -1.38 & -0.33 & $2.07^{\star}$ & $7.59^{\star \star}$ & $6.60^{\star \star}$ & 1.52 & 1.48 & 1.90 & $6.52^{\star \star}$ & $4.10^{\star \star}$ & $1.83^{\star \star}$ & $-4.51^{\star \star}$ & $-1.85^{\star \star}$ & $3.43^{\star \star}$ \\
\hline \multirow[t]{3}{*}{ PHOB } & B & 0.01 & -0.10 & 0.00 & 0.05 & 0.00 & -0.07 & 0.00 & 0.05 & 0.01 & 0.01 & 0.01 & -0.01 & 0.01 & 0.00 & 0.15 & -0.17 & -0.10 & 0.52 \\
\hline & $\beta$ & 0.10 & -0.03 & 0.00 & 0.05 & 0.03 & -0.02 & 0.00 & 0.05 & 0.09 & 0.09 & 0.00 & -0.01 & 0.01 & 0.02 & 0.14 & -0.14 & -0.09 & 0.44 \\
\hline & $t$ & $5.43^{\star \star}$ & $-1.85^{\dagger}$ & 0.20 & $2.97^{\star \star}$ & 1.00 & -1.29 & 0.09 & $2.99^{\star \star}$ & $3.62^{\star *}$ & $3.83^{\star *}$ & 0.15 & -0.38 & 0.95 & 0.78 & $8.67^{\star \star}$ & $-7.56^{\star \star}$ & $-5.40^{* *}$ & $28.25^{\star \star}$ \\
\hline \multirow[t]{3}{*}{ PAR } & B & 0.01 & 0.03 & 0.03 & 0.10 & 0.00 & 0.07 & 0.02 & 0.10 & 0.01 & 0.01 & 0.15 & 0.01 & 0.07 & 0.01 & 0.24 & -0.15 & -0.17 & 0.47 \\
\hline & $\beta$ & 0.11 & 0.01 & 0.02 & 0.10 & -0.01 & 0.02 & 0.02 & 0.10 & 0.15 & 0.07 & 0.04 & 0.01 & 0.06 & 0.06 & 0.21 & -0.11 & -0.15 & 0.39 \\
\hline & $t$ & $5.68^{\star \star}$ & 0.48 & 1.27 & $6.03^{\star *}$ & -0.32 & 1.33 & 1.10 & $6.07^{\star \star}$ & $5.65^{\star \star}$ & $2.96^{\star \star}$ & $3.31^{\star *}$ & 0.65 & $4.76^{\star \star}$ & $2.93^{\star \star}$ & $13.49^{\star \star}$ & $-6.49^{\star \star}$ & $-9.46^{* *}$ & $25.42^{\star \star}$ \\
\hline \multirow[t]{3}{*}{ PSY } & B & 0.01 & 0.04 & 0.01 & 0.09 & 0.00 & 0.07 & 0.01 & 0.09 & 0.01 & 0.01 & 0.16 & 0.00 & 0.06 & 0.00 & 0.21 & -0.13 & -0.12 & 0.50 \\
\hline & $\beta$ & 0.12 & 0.01 & 0.01 & 0.09 & 0.03 & 0.02 & 0.01 & 0.09 & 0.12 & 0.10 & 0.05 & 0.00 & 0.06 & 0.04 & 0.20 & -0.11 & -0.11 & 0.44 \\
\hline & $t$ & $6.53^{\star \star}$ & 0.71 & 0.57 & $5.84^{* \star}$ & 1.05 & 1.39 & 0.44 & $5.87^{\star \star}$ & $4.57^{\star \star}$ & $4.51^{\star \star}$ & $3.84^{* *}$ & -0.12 & $4.37^{\star \star *}$ & $1.74^{\dagger}$ & $12.51^{\star \star}$ & $-6.10^{* *}$ & $-6.87^{\star \star}$ & $29.35^{\star \star}$ \\
\hline
\end{tabular}

${ }^{*} p<0.05,{ }^{* *} p<0.01 .0 .05+0.1$. SOM, somatization; O-C, obsessive-compulsiveness; I-S, interpersonal sensitivity; DEP, depression; ANX, anxiety; HOS, hostility; PHOB, phobic anxiety; PAR, paranoid ideation; PSY, psychoticism; FS, fantasy; EC, empathic concern; PT, perspective taking; PD, personal distress. 
TABLE 5 | Hierarchy regressions predicting the preschool teachers' mental health symptoms in the four working year groups.

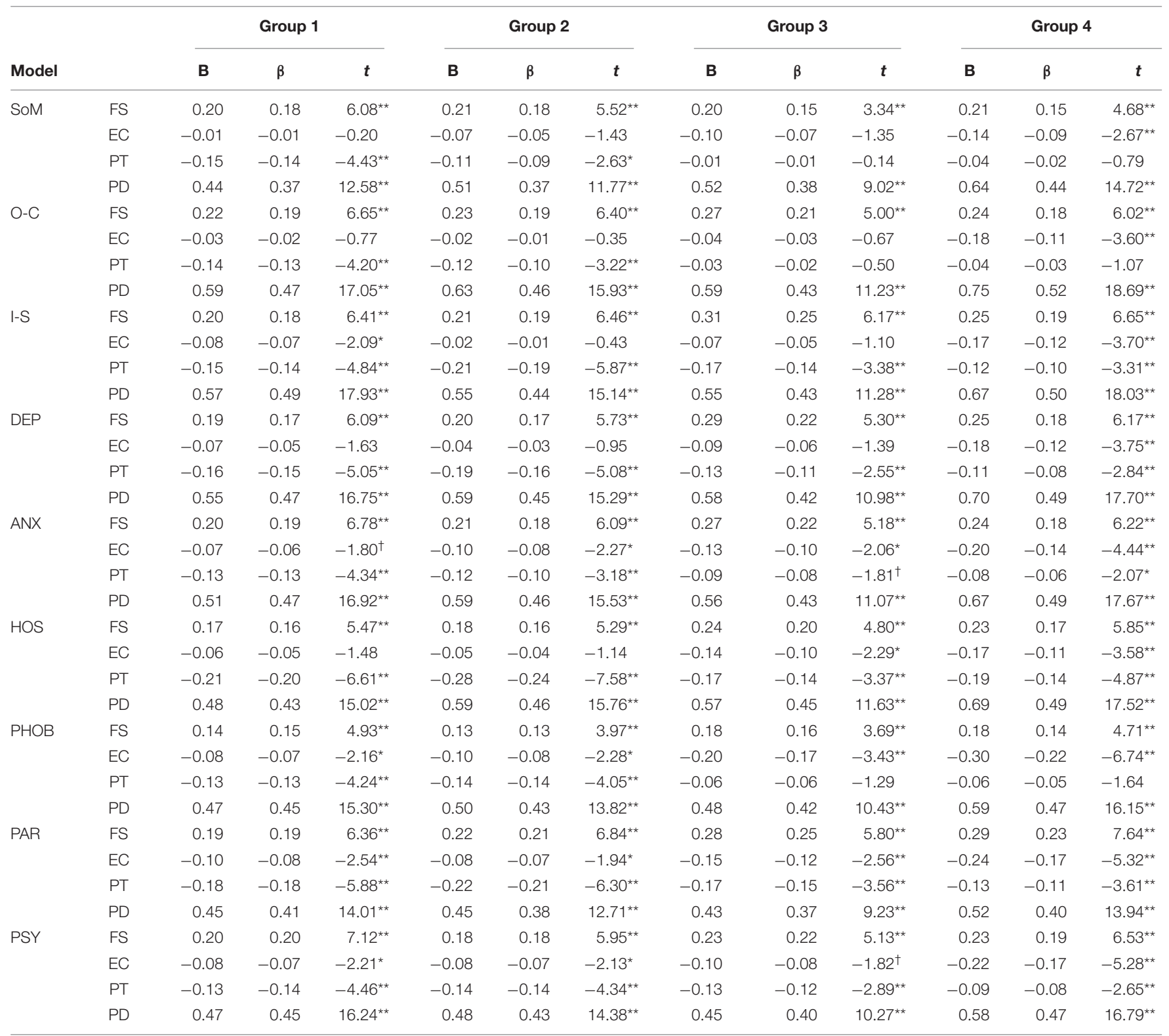

${ }^{*} p<0.05,{ }^{* *} p<0.01 .0 .05+0.1$. SOM, somatization; O-C, obsessive-compulsiveness; I-S, interpersonal sensitivity; DEP, depression; ANX, anxiety; HOS, hostility; PHOB, phobic anxiety; PAR, paranoid ideation; PSY, psychoticism; FS, fantasy; EC, empathic concern; PT, perspective taking; PD, personal distress.

of empathic concern and perspective taking were different across the four teaching experience groups. Although empathic concern negatively predicted anxiety, phobic, anxiety, paranoid ideation, and psychoticism in all the four teaching experience groups, it selectively negatively predicted somatization, obsessivecompulsiveness behavior, interpersonal sensitivity, depression, and hostility only in participants with more than 5 years teaching experience (in the third or four teaching experience group). In contrast, although perspective taking also negatively predicted the similar symptoms with empathic concern in all teaching experience groups, it only negatively predicted somatization, obsessive-compulsiveness behavior, and phobic anxiety for the participants with teaching experience less than 5 years (in the first and second teaching experience groups). That is to say, empathic concern plays a protective role against mental problems mainly in new preschool teachers, whereas empathic concern plays a protective role mainly in experienced preschool teachers.

\section{DISCUSSION}

The present study examined the characters of mental health and empathy in Chinese preschool teachers. Moreover, this study revealed that empathy played both protective and risk roles in preschool teachers' mental health, and these roles were affected by preschool teachers' teaching experience. 


\section{Preschool Teachers' Mental Health}

By examining mental health in a sample covering a wide range of teaching experiences, the present study reveals the general condition and dynamic aspect of Chinese preschool teachers' mental health.

First, the results indicate that as teachers' experience increases, preschool teachers exhibit a trend toward increases in mental health symptoms. This result was supported by a meta-analysis, which indicated that during the period of 1998-2013, Chinese teachers' mental health becomes worse (Yang et al., 2019). However, despite its extreme importance, the mental status of teachers is still worrying.

In addition, the characteristics of the nine symptoms suggested that for each of the four teaching experience groups, obsessive-compulsiveness behavior, somatization, depression, and interpersonal sensitivity were the most serious symptoms, with the severity of somatization and depression increasing faster. Among these symptoms, obsessive-compulsiveness behavior is the most prominent mental health problems for preschool teachers with various teaching experience. It seems that obsessive-compulsiveness behavior is a typical mental problem in teaching professionals, as obsessive-compulsiveness behavior was also found as the most serious mental health problem among Chinese primary and high school teachers (Zeng and $\mathrm{Li}$, 2011). Interpersonal sensitivity is also a typical mental problem especially for the new preschool teachers. Teaching, by nature, is a complex interpersonal interaction, and new teachers have to rebuild their interpersonal relationships, which may contribute to the preschool teachers' interpersonal sensitivity. In addition, the increase in severity of somatization and depression with teaching experience may reflect the process of emotional exhaustion and job burnout, as these two indexes are sensitive to stress and emotional labor (Seery and Corrigall, 2009), which are both typical characters in preschool education (Miller et al., 2019).

\section{Preschool Teachers' Empathy}

The present study found that among preschool teachers, the four dimensions of empathy showed different patterns as teaching experience increased: fantasy remained stable, empathic concern and perspective taking showed a slow decreasing trend, and personal distress showed an increasing trend.

According to a research on student preschool teacher (Huang et al., 2018), the mechanisms underlying the changing pattern of empathy are dehumanization and detachment, which are indexes of job burnout (Haslam and Loughnan, 2014). Preschool teaching typically involves emotional labor, of which emotional engagement is a core part (Philipp and Schüpbach, 2010). Exposure to children's emotions for an extended period could decrease preschool teachers' sensitivity to emotional cues, and empathy, if it is too strong or lasts too long, could increase the risk of emotional exhaustion (Wróbel, 2013; Wacker and Dziobek, 2018). Accordingly, the changes observed in the preschool teachers may reflect a protective mechanism.

\section{The Relationship Between Empathy and Mental Health}

The present study found a relatively complex relationship between empathy and mental health in preschool teachers. These results only partially supported our first hypothesis. This study indicated that empathy dimensions correlate with mental health differently; however, this study also suggested that fantasy and personal distress are risk factors to preschool teachers' mental health, whereas empathic concern and perspective taking play protective roles in preschool teachers' mental health. In addition, the second hypothesis was supported as the result indicated that the relationships between dimensions of empathy and mental health symptoms were different across the four teaching experience groups.

\section{Fantasy and Personal Distress Are Risk Factors to Preschool Teachers' Mental Health}

First, this study revealed that fantasy and personal distress predicted more mental health symptoms in preschool teachers with various teaching experience. In accordance with some previous studies, the present research also proves that, as an important interpersonal skill set, empathic tendencies can also be "risk strengths" (Bubandt and Willerslev, 2015) and may confer risk for internalizing problems (Tone and Tully, 2014).

Among these findings, the result suggesting that personal distress is a risk factor to mental health was observed by many previous studies. For example, personal distress was found to significantly predict the perceived stress in medical staff (Ortiz Barón et al., 2018) and teachers (Vucinic et al., 2020).

However, our result also suggested that fantasy increased susceptibility to mental health symptoms, and this result was somewhat surprising, because fantasy is usually regarded as a cognitive component of empathy (Wu et al., 2012; Karyagina et al., 2017), and some previous research has found the positive function against mental health-related problems. For example, Karyagina et al. (2017) have found that in nurses, both perspective taking and fantasy negatively correlated with professional burnout, which is also a typical index of mental health. However, in the present study, fantasy is proved to be a risk factor to mental health symptoms. An explanation is provided by the Karyagina et al. (2017) study, which investigated the medical staff, who are often exposed to stronger emotional expressions, whereas the participants in this study were teachers whose working environment was different from that of the medical staff. Another recent research conducted in college sample also found that both fantasy and personal distress are negatively associated with neuroticism dimension in Eysenck Personality Questionnaire and positively correlated with the individual's trends of feeling anxiety and stress (Neumann et al., 2016).

This result concerning the risk role of fantasy reminds us to reconsider and interpret carefully the nature and function of fantasy. Fantasy is usually defined as an automatic tendency to imaginatively transpose oneself into fictional situations (Keaton, 2017). According to the description of the items in the IRI (Davis, 1983), fantasy is a trend of automatically imitating or mimicking a fictional character. Therefore, individuals high in fantasy are 
more likely to experience similar negative affect when facing others' emotional suffering. However, more especially designed research is needed to find out the nature and functions of fantasy.

\section{Empathic Concern and Perspective Taking Are Protective Factors in Preschool Teachers' Mental Health}

This study also indicated that empathic concern and perspective taking were negatively related with preschool teachers' mental health problems. These results imply that these two empathy components may be protective factors for preschool teachers' mental health. The positive effects of empathic concern and perspective taking were supported by a large number of research from both medical (Thirioux et al., 2016) and educational fields (Ahmetoglu and Acar, 2016; Bullough, 2019). This result was also supported by a meta-analysis (Longmire and Harrison, 2016) of 269 independent samples, which found positive effects of perspective taking and empathic concern on various outcome domains at work. According to the classical theoretical models of Preston and de Waal (2002) and Decety and Lamm (2006), the mechanism underlying the positive effects of empathic concern and perspective taking may be that both of these two empathy components are based on the self-other distinction and are regulated by the up-down processes, and therefore, individuals high in these two empathy components are less likely to be overwhelmed by the others' distress, more open to the person in distress, and consequently more resistant to mental health problems (Thirioux et al., 2016; Wacker and Dziobek, 2018).

Moreover, this study also found a difference between the roles of empathic concern and perspective taking in preschool teachers' mental health during their working years. This result suggested the protective effects of perspective taking were greater than those of empathic concern. In this study, perspective taking negatively predicted all mental health problems across almost all the four working year groups, whereas empathic concern only negatively predicted symptoms such as phobic anxiety, paranoid ideation, and psychoticism. In addition, empathic concern has a protective effect only in experienced preschool teachers with longer teaching experience. The stronger protective effects of perspective taking were also suggested by other research. For example, Lamothe et al. (2014) found that perspective taking alone might be a protective factor for burnout, whereas empathic concern happens only under the balance of perspective taking. This may because cognitive empathy requires effort to understand the person in distressing experiences while keeping a certain affective distance, whereas empathic concern, by nature, is an emotional component that involves a non-conscious sharing when facing others' suffering.

\section{How Different Empathy Components Correlated With Mental Health}

Overall, our study indicates that as a multidimensional phenomenon, empathy builds upon the cooperation of automatic, emotional, and cognitive processes to cope with the demand raised by environments. For preschool teachers who are surrounded with various emotions and whose job is typically an emotional labor (Philipp and Schüpbach, 2010), different empathy components function differently to help teachers to adapt to their job and keep the balance between self and other (Chiu and Yeh, 2017).

Among the components of empathy, personal distress and fantasy facilitate the overwhelming merging from self to others to feel the others' feeling, which increases one's susceptibility to negative emotions and stresses and consequently results in higher risk of stress and mental health problems (Keaton, 2017; Huang et al., 2018). Empathic concern and perspective taking are based on the distinction between self and others, protect one from being overwhelmed by others' emotion, and consequently help in resisting stress and mental health problems. From this perspective, this study deepened our understanding of the function of empathy and the emotional nature of preschool teaching.

\section{The Role of Preschool Teaching Experience in the Relationship Between Empathy and Mental Health}

The present research also indicates a dynamic relationship between empathic concern, perspective taking, and preschool teachers mental health status across different teaching experience groups. A possible explanation to this result is the psychological nature of teaching experience.

According to Katz's (1972) theoretical framework, preschool teachers' development contains four stages: survival, consolidation, renewal, and maturity stage. The most prominent feature of the earlier career stage, such as the survival and consolidation stages, is that teachers cannot break through the self-centeredness and mainly focus on their own survival and adaptation. Preschool teachers have to use the cognitive tool, for example, perspective taking, to understand the feeling and thoughts of others and consequently to adopt the working task and personal relationship. With the increase of teaching experience, preschool teachers enter the stage of renewal and maturity stages; and empathic concern, which is automatic and affective in nature, may help the teachers feel and understand others' emotions better. From this perspective, this research highlights the role of teaching experience in an emotional context.

\section{THEORETICAL AND PRACTICAL IMPLICATIONS}

From the theoretical perspective, this study deepens and broadens our understanding of empathy, mental health, teaching experience, and their relationship. To begin with, this study implies the complicated role of empathy in individuals' occupations and shed light on the interpersonal nature of empathy (Coutinho et al., 2014). In addition, this study also adds empirical evidence of teachers' developmental stages (Katz, 1972) by using the context of preschool teaching.

The present study also provides practical implications for teachers' mental health. First, to minimize the risk of poor mental health in preschool teachers, screening and professional 
intervention services should be provided at different career stages, especially in preschool teachers with more teaching experience, who may be more susceptible to various mental health symptoms. Second, it is important to take empathy into consideration when designing and implementing intervention programs for teachers' mental health, and both the positive and negative effects of empathy should be taken into consideration (Erera, 1997; Goroshit and Hen, 2014). According to the present study, empathic concern and perspective taking are protective factors to preschool teachers' mental health, and intervention programs can facilitate teachers' mental health by cultivating their empathic concern and perspective taking. Moreover, personal distress and fantasy were found to be potential risk factors underlying preschool teachers' mental health, so it is also necessary to decrease these two components of empathy.

\section{VALUES, LIMITATIONS, AND FUTURE DIRECTIONS}

This study was an important attempt to integrate the potential factors of teachers' mental health. The results provide valuable insight into the risk and protective functions of empathy in teachers' mental health. Furthermore, the Chinese sample of the present study broadens our understanding of this important problem by adding data on non-Western cultures. In addition, the adequate sample size was also an advantage of this research.

This study has several limitations that must be mentioned. First, the cross-sectional design is unable to provide a causal explanation with regard to how empathy affects preservice teachers' mental health. A longitudinal design or intervention research is needed in the future. Second, the sample in the present study included only public preschool teachers and thus does not represent all preschool teachers. Future research should include not only teachers in public preschools but also teachers in private preschools to ensure a fully representative sample. Finally, the participants' mental health and empathy scores were based on self-reports. Although the most widely used measures were utilized in this research, societal stereotypes could bias the evaluation of self-reports. Moreover, although the processes in this study were carried out semi-anonymously, the self-reporting nature of the current study means its results may be affected

\section{REFERENCES}

Ahmetoglu, E., and Acar, I. H. (2016). The correlates of turkish preschool preservice teachers' social competence, empathy and communication skills. Eur. J. Contemp. Educ. 16, 188-197. doi: 10.13187/ejced.2016.16.188

Allan, B. A., Dexter, C., Kinsey, R., and Parker, S. (2016). Meaningful work and mental health: job satisfaction as a moderator. J. Ment. Health 27, 1-7. doi: 10.1080/09638237.2016.1244718

Arbuckle, J. L., and Wothke, W. (1999). AMOS 4.0 User's Guide. Chicago, IL: Small Waters Corporation.

Beijing Municipal Government (2017). Statistics on the Development of Education in Beijing in 2015-2016. Available online at: http://www.beijing.gov.cn/zfxxgk/ 110003/jysytj32/2017-01/11/content_778614.shtml (accessed 01 Nov 2017).

Bowles, T., and Arnup, J. (2016). Should I stay or should I go? Resilience as a protective factor for teachers' intention to leave the teaching profession. Aust. J. Educ. 60, 229-244. doi: 10.1177/0004944116667620 by the socially desirable effect. Therefore, further studies should include multiple methods, including behavior or physiological indicators, to explore the underlying mechanism of preschool teachers' mental health.

\section{DATA AVAILABILITY STATEMENT}

The datasets generated for this study are available on request to the corresponding author.

\section{ETHICS STATEMENT}

The studies involving human participants were reviewed and approved by the Ethic Committees in Capital Normal University. The patients/participants provided their written informed consent to participate in this study.

\section{AUTHOR CONTRIBUTIONS}

$\mathrm{HH}$ and YL performed material preparation and, data collection and analysis. $\mathrm{HH}$ wrote the first draft of the manuscript. YS and $\mathrm{HH}$ performed the funding acquisition. YS conducted the supervision. All authors contributed to the study conception and design, commented on previous versions of the manuscript and, read and approved the final manuscript.

\section{FUNDING}

This research was supported by the National Natural Science Foundation of China (Project 31872782) and the Science and Technology Project of Beijing Education Commission (SQKM201710028022).

\section{ACKNOWLEDGMENTS}

We are grateful to all the individuals who have participated in our study or provided assistance.

Bubandt, N., and Willerslev, R. (2015). The dark side of empathy: mimesis, deception, and the magic of alterity. Comp. Stud. Soc. Hist. 57, 5-34. doi: 10.1017/S0010417514000589

Buck, R., Powers, S. R., and Hull, K. S. (2017). Measuring emotional and cognitive empathy using dynamic, naturalistic, and spontaneous emotion displays. Emotion 17, 1120-1136. doi: 10.1037/emo0000285

Bullough, R. V. (2019). Empathy, teaching dispositions, social justice and teacher education. Teach. Teach. 25, 507-522. doi: 10.1080/13540602.2019.16 02518

Capone, V., and Petrillo, G. (2018). Mental health in teachers: relationships with job satisfaction, efficacy beliefs, burnout and depression. Curr. Psychol. 6, 1-10. doi: $10.1007 /$ s12144-018-9878-7

Carnicer, J. G., and Calderón, C. (2014). Empathy and coping strategies as predictors of well-being in Spanish university students. Electronic J. Res. Educ. Psychol. 12, 129-146. doi: 10.14204/ejrep.32. 13117 
Chekroud, A. M., Loho, H., and Krystal, J. H. (2017). Mental illness and mental health. Lancet Psychiatry 4, 276-277. doi: 10.1016/S2215-0366(17)30088-3

Chen, X. (2009). Survey of mental health states and job born-out of young kindergarten teachers in Private kindergartens. J. Chongqing Normal University $26,130-134$.

Chinese Ministry of Education (2012). Interim Measures for Supervision and Evaluation of Preschool Education. Available online at: http://www.gov.cn/gzdt/ 2012-03/07/content_2085962.htm (accessed 03 July 2012).

Chiu, C., and Yeh, Y. (2017). In your shoes or mine? Shifting from other to self perspective is vital for emotional empathy. Emotion 18, 39-45. doi: 10.1037/ emo0000346

Coutinho, J. F., Patrícia, O., and Decety, J. (2014). Neurosciences, empathy, and healthy interpersonal relationships: recent findings and implications for counseling psychology. J. Counsel. Psychol. 61, 541-548. doi: 10.1037/ cou0000021

Dai, Y., Zhang, B., Sun, H., Li, Z., Shen, L., and Liu, Y. (2015). Prevalence and correlates of psychological symptoms in Chinese doctors as measured with the SCL-90-R: a meta-analysis. Res. Nur. Health 38, 369-383. doi: 10.1002/nur. 21673

Davis, M. H. (1983). Measuring individual differences in empathy: evidence for a multidimensional approach. J. Personal. Soc. Psychol. 44, 113-126. doi: 10.1037/ 0022-3514.44.1.113

Decety, J., and Lamm, C. (2006). Human empathy through the lens of social neuroscience. Sci. World J. 6, 1146-1163. doi: 10.1100/tsw.2006.221

Dekel, R., Siegel, A., Fridkin, S., and Svetlitzky, V. (2017). The double-edged sword: the role of empathy in military veterans' partners distress. Psychol. Trauma 10, 216-224. doi: $10.1037 /$ tra0000265

Derogatis, L. R. (1992). The Symptom Chechlist-90-revised. Minneapolis, MN: NCS.

Dods, J. (2016). Teacher candidate mental health and mental health literacy. Exceptional. Educ. Int. 26, 42-61.

Erera, P. I. (1997). Empathy training for helping professionals. J. Soc. Work Educ. 33, 245-260. doi: 10.1080/10437797.1997.10778868

Fan, H., Li, J., Zhao, M., and Li, H. (2016). Mental health of kindergarten teachers: meta-analysis of studies using SCL-90 scale. Adv. Psychol. Sci. 24, 9-20. doi: 10.3724.sp.J.2016.00009

Feng, Z., and Zhang, D. (2001). Study on the validity of the symptom check list-90 of Chinese version. J. Third Mil. Med. University 23, 481-483.

Franken, K., Lamers, S., Ten, P. K., Bohlmeijer, E. T., and Westerhof, G. J. (2018). Validation of the mental health continuum-short form and the dual continua model of well-being and psychopathology in an adult mental health setting. J. Clin. Psychol.74, 2187-2202. doi: 10.1002/jclp.22659

Fulton, C. L. (2012). Mindful awareness and compassion, and empathy and anxiety in counselor trainees. ProQuest Dissertations and Theses. Available online at: http://jerome.stjohns.edu:81/login?url=http://search.proquest.com/ docview $/ 1080792046$ ? accountid $=14068$

Gaines, R. E., Osman, D. J., Maddocks, D. L. S., Warner, J. R., Freeman, J. L., and Schallert, D. L. (2019). Teachers' emotional experiences in professional development: where they come from and what they can mean. Teach. Teach. Educ. 77, 53-65. doi: 10.1016/j.tate.2018.09.008

Gambin, M., and Sharp, C. (2018). Relations between empathy and anxiety dimensions in inpatient adolescents. Anxiety Stress Coping 31, 447-458. doi: 10.1080/10615806.2018.1475868

Goroshit, M., and Hen, M. (2014). Does emotional self-efficacy predict teachers' self-efficacy and empathy? J. Educ. Train. Stud. 2, 16-25. doi: 10.11114/jets.v2i3. 359

Grayson, J. L., and Alvarez, H. K. (2008). School climate factors relating to teacher burnout: a mediator model. Teach. Teach. Educ. 24, 1360-1363. doi: 10.1016/j. tate.2007.06.005

Halpern, J. (2003). What is clinical empathy? J. Gen. Intern. Med. 18, 670-674. doi: 10.1046/j.1525-1497.2003.21017.x

Harding, S., Morris, R., Gunnell, D., Ford, T., and Hollingworth, W. (2019). Is teachers' mental health and wellbeing associated with students' mental health and wellbeing? J. Affect. Disord. 253, 460-466. doi: 10.1016/j.jad.2019. 03.046

Haslam, N., and Loughnan, S. (2014). Dehumanization and infrahumanization. Annu. Rev. Psychol. 65, 399-423. doi: 10.1146/annurev-psych-010213-1 15045
Huang, H., Liu, Y., and Chen, Y. (2018). Preservice preschool teachers' responses to bullying scenarios: the roles of years of study and empathy. Front. Psychol. 9:175. doi: 10.3389/fpsyg.2018.00175

Huang, H., and Su, Y. (2013). The Development Trajectories and the Underlying Mechanisms of Cognitive and Affective Empathy, Unpublished Dissertation, Peking University, Beijing.

Jennings, P. A., Brown, J. L., Frank, J. L., Doyle, S., Oh, Y., Davis, R., et al. (2017). Impacts of the CARE for teachers program on teachers' social and emotional competence and classroom interactions. J. Educ. Psychol. Adv. Online Publ. 109, 1010-1028. doi: 10.1037/edu0000187

Karyagina, T. D., Kukhtova, N. V., Olifirovich, N. I., and Shermazanyan, L. G. (2017). Professionalization of empathy and predictors of helping professionals' burnout. Counsel. Psychol. Psychother. 25, 39-58. doi: 10.17759/ cpp.2017250203

Katz, L. G. (1972). Developmental stages of preschool teachers. Elem. Sch. J. 73, 50-54. doi: $10.1086 / 460731$

Keaton, S. A. (2017). Interpersonal Reactivity Index (IRI).in The Sourcebook of Listening Research: Methodology and Measures. eds D. L. Worthington, and G. D. Bodie (Hoboken, NJ: John Wiley \& Sons, IncL).

Keyes, C., Shmotkin, D., and Ryff, C. (2002). Optimizing well-being: the empirical encounter of two traditions. J. Personal. Soc. Psychol. 82, 1007-1022. doi: 10. 1037/0022-3514.82.6.1007

Kim, K. (2017). To feel or not to feel: empathy and physician burnout. Acad. Psychiatry 42, 157-158. doi: 10.1007/s40596-017-0871-5

Lamothe, M., Boujut, E., Zenasni, F., and Sultan, S. (2014). To be or not to be empathic: the combined role of empathic concern and perspective taking in understanding burnout in general practice. Biomed. Central Fam. Pract. 15:1-7. doi: 10.1186/1471-2296-15-15

Lee, M., Pekrun, R., Taxer, J. L., Schutz, P. A., Vogl, E., and Xie, X. (2016). Teachers' emotions and emotion management: integrating emotion regulation theory with emotional labor research. Soc. Psychol. Educ. 19, 1-21. doi: 10.1007/ s11218-016-9359-5

Longmire, N., and Harrison, D. A. (2016). Seeing their side, feeling their pain: outcomes of perspective-taking and empathic concern at work. Acad. Manag. Аnnu. Meet. Proc. 2016:17923. doi: 10.5465/AMBPP.2016.233

Macritchie, V., and Leibowitz, S. (2010). Secondary traumatic stress, level of exposure, empathy and social support in trauma workers. South Afr. J. Psychol. 40, 149-158. doi: 10.1177/008124631004000204

McLean, L., and Connor, C. M. (2018). Relations between third grade teachers' depressive symptoms and their feedback to students, with implications for student mathematics achievement. Sch. Psychol. Q. 33, 272-282. doi: 10.1037/ spq0000225

Mérida-López, S., Extremera, N., and Rey, L. (2017). Emotion-regulation ability, role stress and teachers' mental health. Occup. Med. 67, 540-545. doi: 10.1093/ occmed/kqx125

Mevarech, Z. R., and Maskit, D. (2015). The teaching experience and the emotions it evokes. Soc. Psychol. Educ. 18, 241-253. doi: 10.1007/s11218-014-9286-2

Miller, L., Musci, R., D’Agati, D., Alfes, C., Beaudry, M. B., Swartz, K., et al. (2019). Teacher mental health literacy is associated with student literacy in the adolescent depression awareness program. Sch. Ment. Health 11, 357-363. doi: 10.1007/s12310-018-9281-4

Neumann, D. L., Chan, R. C. K., Wang, Y., and Boyle, G. J. (2016). Cognitive and affective components of empathy and their relationship with personality dimensions in a Chinese sample. Asian J. Soc. Psychol. 19, 244-253. doi: 10. 1111/ajsp. 12138

Ortiz Barón, M. J., Etxebarria, B. I., Apodaca, U. P., Conejero, L. S., and Pascual, J. A. (2018). Moral emotions associated with prosocial and antisocial behavior in school-aged children. Psicothema 30, 82-88. doi: 10.7334/psicothema2016.143

Peck, N. F., Maude, S. P., and Brotherson, M. J. (2015). Understanding preschool teachers' perspectives on empathy: a qualitative inquiry. Early Child. Educ. J. 43, 169-179. doi: 10.1007/s10643-014-0648-3

Philipp, A., and Schüpbach, H. (2010). Longitudinal effects of emotional labour on emotional exhaustion and dedication of teachers. J. Occup. Health Psychol. 15, 494-504. doi: 10.1037/a0021046

Preston, S. D., and de Waal, F. B. M. (2002). Empathy: its ultimate and proximate bases. Behav. Brain Sci. 25, 1-71. doi: 10.1017/S0140525X020 00018 
Santamaría-García, H., Baez, S., García, A. M., Flichtentrei, D., Prats, M., Mastandueno, R., et al. (2017). Empathy for others' suffering and its mediators in mental health professionals. Sci. Rep. 7:6391. doi: 10.1038/s41598-01706775-y

Seery, B. L., and Corrigall, E. A. (2009). Emotional labor: links to work attitudes and emotional exhaustion. J. Manag. Psychol. 24, 797-813. doi: 10.1108/ 02683940910996806

Stevens, J. P. (2002). Applied Multivariate Statistics for the Social Sciences, 4th Edn. Mahwah, NJ: Lawrence Erlbaum.

Thirioux, B., Birault, F., and Jaafari, N. (2016). Empathy is a protective factor of burnout in physicians: new neuro-phenomenological hypotheses regarding empathy and sympathy in care relationship. Front. Psychol. 7:763. doi: 10.3389/ fpsyg.2016.00763

Tone, E. B., and Tully, E. C. (2014). Empathy as a "risky strength": a multilevel examination of empathy and risk for internalizing disorders. Dev. Psychopathol. 26, 1547-1565. doi: 10.1017/S0954579414001199

Vucinic, V., Stanimirovic, D., Gligorovic, M., Jablan, B., and Marinovic, M. (2020). Stress and empathy in teachers at general and special education schools. Int. J. Disabil. Dev. Educ. doi: 10.1080/1034912X.2020.17 27421

Wacker, R., and Dziobek, I. (2018). Preventing empathic distress and social stressors at work through nonviolent communication training: a field study with health professionals. J. Occup. Health Psychol. 23, 141-150. doi: 10.1037/ ocp0000058

Williams, C. (1989). Empathy and burnout in male and female helping professionals. Res. Nurs. Health 12, 169-178. doi: 10.1002/nur.4770120307

World Health Organization (2006). Constitution of the World Health Organization. Available online at: http://www.who.int/governance/eb/who_constitution_en. pdf (accessed October 2016).

Wróbel, M. (2013). Can empathy lead to emotional exhaustion in teachers? the mediating role of emotional labor. Int. J. Occup. Med. Environ. Health 26, 581-592. doi: 10.2478/s13382-013-0123-1
$\mathrm{Wu}$, N., Li, Z., and Su, Y. (2012). The association between oxytocin receptor gene polymorphism (OXTR) and trait empathy. J. Affect. Dis. 138, 468-472. doi: 10.1016/j.jad.2012.01.009

Yang, R., You, X., Zhang, Y., Lian, L., and Feng, W. (2019). Teachers' mental health becoming worse: the case of China. Int. J. Educ. Dev. 70:102077 doi: 10.1016/j.ijedudev.2019.102077

Yekta, M. S., Zardkhaneh, S. A., and Shahmohammadi, K. (2014). Effects of using problem solving and anger management package on mental health and teaching style of preschool teachers. Journal of School Psychology 2, 98-117. doi: 10.1016/j.childyouth.2010.04.024

Zaki, J. (2019). Integrating empathy and interpersonal emotion regulation. Annu. Rev. Psychol. 71, 517-540. doi: 10.1146/annurev-psych-010419-050830

Zeng, M., and Li, H. (2011). Meta-analysis of primary and secondary school teachers' mental health in China. China J. Health Psychol. 19, 1348-1350.

Zhang, L., Zhao, J., Xiao, H., Zheng, H., Xiao, Y., Chen, M., et al. (2014). Mental health and burnout in primary and secondary school teachers in the remote mountain areas of Guangdong province in the people's republic of China. Neuropsychiatr. Dis. Treat. 10, 123-130. doi: 10.2147/NDT.S56020

Zhang, W., Li, H., Gong, Y., and Ungar, M. (2013). Stressful events and depression among Chinese adolescents: the mitigating role of protective factors. Sch. Psychol. Int. 34, 501-513. doi: 10.1177/0143034312472760

Conflict of Interest: The authors declare that the research was conducted in the absence of any commercial or financial relationships that could be construed as a potential conflict of interest.

Copyright (C) 2020 Huang, Liu and Su. This is an open-access article distributed under the terms of the Creative Commons Attribution License (CC BY). The use, distribution or reproduction in other forums is permitted, provided the original author(s) and the copyright owner(s) are credited and that the original publication in this journal is cited, in accordance with accepted academic practice. No use, distribution or reproduction is permitted which does not comply with these terms. 